\title{
Historiando a dimensão ambiental nos programas escolares gaúchos
}

\author{
Sônia Balvedi Zakrzevski ${ }^{1}$ \\ Universidade Regional Integrada do Alto Uruguai e das Missões \\ Michèle Sato $^{2}$ \\ Universidade Federal de Mato Grosso
}

resumo: Este trabalho caracteriza-se como uma pesquisa bibliográfica na qual procuramos resgatar a história da Educação Ambiental (EA) na escola pública gaúcha, a partir da leitura e análise dos Programas de Ensino Oficiais do Estado do Rio Grande do Sul, propostos da década de 1930 a 2000. Percebemos que, ao longo da história, a EA esteve vinculada a diferentes valores e interesses e por isso tem apresentado objetivos, orientações metodológicas e políticas distintas. $\mathrm{Na}$ maior parte desse período, ela foi vinculada ao ensino de Ciências Naturais e abordada como conteúdo ou matéria. Apenas no final dos anos 90 deixa de ser uma temática marginalizada e as propostas oficiais sugerem sua integração à totalidade do currículo escolar. No início deste milênio, a EA gaúcha começa a apresentar uma identidade política própria.

palavras-chave: Educação Ambiental, Currículo, Escola.

abstract: This paper is a bibliographic research in which we rescue the history of Environmental Education (EA) in public schools in Rio Grande do Sul, by reading and analyzing the Official Teaching Programs in this state, from 1930 to 2000 . We realized that during this period EA was connected to different values and interests and that this is the reason why it has shown distinct objectives, methodological orientations and policies. It has being associated to the Natural Sciences teaching and taught as a subject, only. It was just in the end of the 90's that it stopped being a marginalized subject, and the official proposes propounded its integration to the totality

\footnotetext{
1 e-mail: sbz@uri.com.br

2 e-mail: michelesato@gmail.com
} 
of the school curriculum. In the beginning of this millennium, Environmental Education started to present its own political identity.

keywords: Environmental education, Curriculum, Schools.

\section{Introdução}

A Educação Ambiental (EA) é uma modalidade complexa da educação que pode ser caracterizada por uma grande diversidade de teorias e práticas, originadas em função de diferentes concepções de educação, de meio ambiente, de desenvolvimento (SAUVÉ; ORELLANA, 2001). Ao longo da história, esteve associada a "diferentes matrizes de valores e interesses, gerando um quadro bastante complexo de educações ambientais com orientações metodológicas e políticas bastante variadas" (CARVALHO, 1998, p. 124). A EA tem sido abordada de diferentes modos: como um conceito, como um processo, como uma orientação curricular, como uma matéria, como um enfoque holístico (GOUGH, 1997 apud ORELLANA, 2001), e também tem apresentado objetivos diversos: a conservação da natureza, o gerenciamento de recursos, a resolução de problemas ambientais, a compreensão do ecossistema, a melhoria dos espaços habitados pelo ser humano, a discussão das questões ambientais globais, etc. No Brasil, a educação ambiental apresenta-se, em sua forte estrutura política, associada ao campo da militância ecologista e enraizada em movimentos sociais demarcados pela contracultura. $\mathrm{Na}$ vanguarda dos anos 60, a Educação Ambiental nasce com outros movimentos e diferencia-se de outras educações, permitindo que o "ambiente" não seja mero adjetivo neutro da educação, mas se consubstancie como um substantivo político de lutas.

Neste trabalho, que se caracteriza como uma pesquisa bibliográfica, procuramos resgatar a história da EA na escola pública gaúcha, a partir da leitura e análise dos Programas de Ensino Oficiais do Estado do Rio Grande do Sul (RS). 


\section{A questão ambiental antes dos anos 70: o ambiente como um expediente pedagógico que permitia implicar ativamente os alunos}

Os primeiros programas educacionais oficiais para a escola pública gaúcha são elaborados no final da década de 30. Através da análise desses programas, diagnosticamos que o estudo do ambiente era proposto no Programa de Estudos Naturais (RIO GRANDE DO SUL, 1940), estando presente nos objetivos gerais dessa matéria:

Prover a criança de conhecimentos e experiências da Natureza e do mundo dos fenômenos [...]; Criar hábitos de observação, comparação e apreciação, no contato direto com a natureza, estimular o desejo de novos esclarecimentos e a organização das idéias, formar espíritos reflexivos que busquem não só explicar os problemas práticos, como estabelecer relações para "perceber" e "sentir" a ordem existente na natureza, a interdependência dos seres e encontrar em toda esta perfeição a revelação de uma inteligência criadora suprema (p. 71).

No documento, encontram-se recomendações para serem privilegiadas as atividades de observação do ambiente natural. O ensino de Ciências deveria estimular o gosto pelo estudo e pelo contato com a natureza, de modo que os alunos construíssem conhecimentos em torno da interdependência dos seres, bem como das leis, definições e princípios a eles relacionados. Também deveriam "estimular atitudes de bondade e proteção para com os animais que prestassem serviços ao homem, e de reação aos que lhe fossem nocivos” (p. 79).

O programa tinha implícita uma concepção empirista, no que se refere ao alcance do conhecimento, enfatizando a dimensão afetiva em relação ao ambiente. A idéia de natureza ali presente reflete a visão de "harmonia preestabelecida" por Deus na criação, na qual a ordem natural depende absolutamente dos desígnios divinos. A escola, desse modo, repassa às crianças a idéia de que “o Deus cristão é transcendente, tendo criado a natureza com base num plano e podendo, eventualmente, intervir alterando a ordem natural dos fenômenos" 
(ABRANTES, 1998, p. 59) e que não há qualquer ideal de ordem que se imponha objetivamente a Deus.

Também a superioridade do ser humano frente aos demais seres da natureza (proposição que ainda se mantém nos livros didáticos atuais) merece destaque. Isso pode ser verificado através da visão antropocêntrica dos animais e de suas funções, a qual condiciona e predispõe, favoravelmente ou não, algumas espécies: os animais fazem parte do que poderíamos denominar "nicho humano", no qual o valor dos mesmos não tem por base suas características ecológicas, mas uma ética utilitarista, que considera os animais e a natureza apenas em função de seu valor de uso, de sua utilidade para o ser humano, reforçando o postulado de que as diferentes espécies somente existem em função da espécie humana. A visão utilitarista sobre a natureza ainda permanece como um legado herdado pelas orientações da Modernidade, com fortes discursos que privilegiam a racionalidade em detrimento de outras dimensões éticas pela vida propriamente dita. Felizmente, porém, algumas teorias da Antropologia Clássica também estão sendo revistas, com desafios às teorias exageradamente sociocêntricas, para uma visão mais integrada do diálogo entre a natureza e a cultura.

A partir de 1956, as discussões para a elaboração de novas diretrizes oficiais para a educação são intensificadas. A Secretaria Estadual de Educação do Rio Grande do Sul começa a enfatizar Os Estudos Naturais na Escola Primária, reconhecendo que "os estudos naturais, abrindo os olhos da criança para a natureza que a cerca, levamna a amá-la cada vez mais, pois oferecem ricas oportunidades para muitas lições de moral, de civismo, de ordem, de disciplina, despertando o amor à verdade e o afeto aos demais seres da natureza" (RIO GRANDE DO SUL, 1956, p. 26).

Estabelece que os Estudos Naturais na Escola Primária deveriam despertar na criança o interesse pela vida dos animais e das plantas em seu meio natural; prover o educando de conhecimentos sobre seres e fenômenos naturais, despertando e afirmando os sentimentos de bondade, de amor e respeito à natureza; formar hábitos de observação, investigação, comparação e apreciação, no contato 
direto com a natureza, levando a criança a redescobrir verdades científicas, afastando assim a idéia do falso sobrenatural, das crendices e superstições, através da valorização da verdade e desenvolvimento do espírito científico; despertar na criança sentimentos e emoções, desenvolvendo o senso estético e religioso, a fim de formar espíritos reflexivos, capazes de "perceber" e "sentir" a ordem existente na natureza, a interdependência dos seres e a revelação da suprema inteligência, causa de toda perfeição (RIO GRANDE DO SUL, 1956). $\mathrm{Na}$ época, toda forma de saber construída fora dos espaços escolarizados foi rejeitada, atribuindo um caráter demasiadamente alto às ciências, com negligência aos múltiplos saberes do mosaico do conhecimento humano.

Nos anos 50 e 60, através de atividades agrícolas, os professores das escolas gaúchas deveriam despertar e manter o interesse pela natureza e pela terra, em especial, fazendo perceber as possibilidades do Brasil em relação ao aproveitamento de suas riquezas naturais, principalmente as relacionadas com a vida agrícola da localidade; despertar ou manter a mentalidade agrícola na criança, dignificando essa forma de trabalho; adaptar a escola às peculiaridades do meio; vitalizar o ensino; orientar vocações; difundir técnicas científicas da agricultura moderna, demonstrando as vantagens da adoção dos processos racionais, a fim de formar atitude de receptividade em relação ao trabalho agrícola, em bases científicas. Ainda hoje, diversas percepções acerca da educação conduzem ao equivocado raciocínio da educação tecnicista, voltada à formação profissional e habilidades próprias ao mercado de trabalho.

Até o início da década de 50, o meio ambiente era tratado pela escola gaúcha como natureza, que deveria ser apreciada e preservada. A natureza era entendida como o ambiente original e puro do qual os seres humanos estão dissociados e no qual devem aprender a relacionar-se para enriquecer a qualidade do "ser". O ambiente era visto pela escola como um expediente pedagógico que permitia implicar ativamente os alunos; por essa razão, as estratégias privilegiadas eram de imersão do aluno na natureza. É importante ressaltar que, nas referidas décadas de 50 e 60, houve um grande estímulo à criação, nas escolas 
rurais, da Liga dos Amigos da Natureza. Os objetivos dessa liga eram de "integrar na comunidade escolar a criança recém-ingressada na mesma" e de "formar mentalidade agrícola nos alunos". Entre as atividades sugeridas para a Liga estavam o cultivo de plantas ornamentais (em canteiros ou vasos) e a manutenção de um aquário na sala de aula, ambos com finalidade de ornamentação e observação; realizar excursões, aulas ao ar livre, etc. a fim de estabelecer contato com seres e fenômenos da natureza; construir abrigos para pássaros (pequenas casas de madeira). Essas atividades eram consideradas importantes para a formação de hábitos, atitudes e conceitos, e por permitir objetivar as aulas e globalizar o ensino, por exemplo, na contagem e outros cálculos em torno das plantas, dos canteiros, dos dias gastos para a germinação, etc. (SILVA, 1970)

Também a Secretaria de Educação do Rio Grande do Sul estimula, a partir de meados da década de 50, mas especialmente a partir dos anos 60, as comemorações do Dia da Árvore, que deveriam ser relacionadas com os trabalhos regulares do Clube Agrícola, quando o mesmo funcionasse na escola. Recomendavam que deveria existir um trabalho preparatório, através do desenvolvimento de unidades didáticas que viessem a globalizar as atividades, para que o trabalho não se tornasse um mero formalismo, sem valor educativo apreciável e sem influência no comportamento do educando. Persistem comemorações pontuais, ainda nos dias atuais, em datas específicas, saindo das regiões rurais e abrangendo espaços urbanos, em cada Estado nacional e inclusive no cenário internacional.

Os professores eram estimulados através de orientações repassadas na Revista do Professor/RS a discutir com os alunos a significação dos vegetais na vida do ser humano, ou seja, o seu emprego na alimentação, indústria, medicina, ornamentação; a função das florestas e a necessidade do cultivo de árvores; conhecimento de espécies existentes na comunidade; estudo das condições indispensáveis à vida vegetal. Uma enormidade de sugestões de atividades e experiências era proposta aos professores para os trabalhos em torno do Dia da Árvore: traçar um código ou regras de conduta em relação às árvores e à natureza; organizar listas de árvores existentes no terreno da 
escola, da casa, da localidade, do Estado ou País; pesquisar contos, adivinhações, poesias, descrições em relação ao conteúdo; realizar excursões; conhecer histórias e lendas relativas à flora brasileira; conhecer o Código Florestal Brasileiro; escolher uma árvore para ser plantada na escola, tornando-a a "árvore da classe”; colocar nas árvores da escola pequenas tabuletas com o nome comum das mesmas, com poesias ou trechos de autores, os quais deveriam despertar e incentivar $\mathrm{o}$ amor e respeito à árvore e à natureza, em geral, etc.

A realização de excursões era muito estimulada, pois, segundo a posição da Secretaria de Educação do Estado, oportunizam o contato com a natureza, oferecendo-lhes possibilidades de observação direta, para aquisição de experiências e conhecimentos, em situação real, bem como para formação de atitudes e hábitos desejáveis. A escola deveria estimular não somente as crianças, mas as atividades escolares deveriam alicerçar o Culto à Árvore por parte do povo em geral, num atributo de gratidão e reconhecimento pelo muito que recebemos do reino vegetal.

Fazendo uma breve análise dos conteúdos e objetivos propostos através dos programas da SEC/RS às escolas nesse período, é possível perceber o comprometimento da educação com a "concretização de um projeto de desenvolvimento social e econômico embasado na atividade urbano-industrial" (GRITTI, 1999, p. 142). As práticas políticas, econômicas e sociais determinam as decisões educacionais; portanto, o currículo proposto para o ensino foi fruto das opções tomadas no interior dessas práticas.

De meados da década de 50 a meados da década de 60, o ambiente que era entendido apenas como natureza a ser amada, respeitada e apreciada começa a ser apresentado também como um recurso a ser explorado. Embora esforços tenham sido envidados para modificar essa percepção sobre a EA, para uma parcela significativa da sociedade o ambiente ainda é concebido como fato externo a ser observado ou apreciado, não havendo, portanto, um debate no campo político, o que sustenta a permanência da mesma visão ingênua sobre a natureza, a sociedade e o sujeito.

Em 1959, são elaborados e publicados, em caráter experimental, novos programas para o estudo das disciplinas existentes no curso 
primário. Em 1962, é reconhecido o êxito dos mesmos e em 1964 eles são publicados, ficando em vigor até o início dos anos 70. As Ciências Naturais que enfatizavam o estudo da natureza começam, a partir do novo Programa Experimental de Ciências Naturais para o ensino primário, a ser constituídas por conteúdos de Botânica, Mineralogia, Geologia, Petrografia e Higiene. Um dos grandes objetivos da Educação em Ciências Naturais na escola era apresentar as formas de aproveitamento dos recursos que o solo oferece, argumentando que a exploração e a industrialização dos recursos naturais de um país representam as colunas mais rigorosas de seu progresso e engrandecimento.

Os recursos da natureza eram considerados como "nossos recursos", e o fato de serem vistos "como meras propriedades pertencentes a unidades políticas impede a percepção do valor intrínseco da natureza" (GRÜN, 1996, p. 46). No Programa, estava implícito que o ser humano não está apenas separado da natureza, mas também é dono dela, gerando um dualismo entre sujeito e objeto, entre seres humanos e natureza.

O sujeito é o usuário (stakeholder) das tecnologias e os recursos naturais (carvão, petróleo, solo, etc.) são vistos como materiais capazes de dar sustentação a essa tecnologia. A própria palavra "recurso" encerra um caráter eminentemente econômico, de uso e abuso de algo para geração de benefícios humanos. Extrapola-se a capacidade capitalista para "recursos humanos", como se a vida tivesse um preço a ser pago, no engodo do "reparo", do "manejo" ou até do "castigo legal". Ora, a vida não pode ser avaliada somente nas esteiras de parâmetros financeiros, senão colocada num vasto campo ético e político de transformação social.

Fica explícito nos objetivos que não podemos exaurir "nossos recursos”, pois a produção ficará afetada. Com isso, a escola era forçada a trabalhar em defesa das condições de produção, e a EA desenvolvida era um grande instrumento agenciador a serviço do Capitalismo Mundial Integrado - CMI (GUATTARI, 1991), que coloniza a subjetividade e o desejo humano. Apesar de todo esse estímulo ao processo de exploração da natureza, a escola fazia referência à 
necessidade de "proteger a natureza", de manter "um coeficiente mínimo de vegetação, indispensável ao equilíbrio biológico da região”, a chamar atenção para o "reflorestamento de áreas devastadas, para o cuidado com as queimadas e derrubadas, a erosão e as pragas da lavoura e da criação" (SILVA, 1970, p. 19).

A escola, ao longo desses anos, foi uma instituição que ajudou a promover um projeto nacional comum. Ela também facilitou a adaptação das novas gerações às transformações econômicas, sociais e culturais que ocorriam. $\mathrm{Na}$ escola, considerou-se o currículo como o instrumento por excelência do controle social que se pretendia estabelecer. Coube, assim, a essa instituição inculcar os valores, as condutas e os hábitos 'adequados'. Nesse mesmo momento, a preocupação com a educação vocacional fez-se notar, evidenciando o propósito de ajustar a escola às novas necessidades da economia. Viu-se como indispensável, em síntese, organizar o currículo e conferir-lhe características de ordem, racionalidade e eficiência.

\section{A EA na década de 70: o nascimento do movimento ecologista no RS e o reconhecimento da importância do ensino de ecologia na escola}

A década de 70 marcou o despertar da consciência ecológica no mundo: a problematização do meio ambiente deslocou-se da escala regional-nacional para a escala global, planetária, e o uso do conceito de ambiente como biosfera generalizou-se (VIOLA e LEIS, 1991). O ambiente, que na década de 60 era considerado um recurso a ser gerenciado, passa a ser visto como um problema global, pois o suporte da vida começa a ser ameaçado pela poluição e degradação, pelos riscos de uma guerra nuclear, pela explosão demográfica. Os problemas de degradação do meio ambiente são percebidos como problemas globais e não mais pontuais. A crise ecológica questiona profundamente a teoria do valor-trabalho, que supõe a infinitude dos recursos naturais e a natureza como um objeto passivo desprovido de valor (VIOLA, 1992, p. 69).

Ainda com forte herança na visão utilitarista de resolução de problemas, até hoje a Educação Ambiental é percebida como 
solucionadora dos dilemas ambientais, gerando muito mais frustração do que lutas. Atribuir tamanha responsabilidade somente a ela é considerá-la exclusiva de um campo de produção do conhecimento do qual certamente ela não é capaz de lidar isoladamente. Há um campo do saber pulsante que clama por diversas áreas do conhecimento, e disso talvez decorram as orientações para transversalizá-la no currículo escolar, como produtora e reprodutora de culturas, ao invés de isolá-la em disciplina específica.

A Conferência das Nações Unidas sobre Meio Ambiente (Estocolmo, 1972), o Relatório Meadows (1972) sobre os limites do crescimento, o surgimento do paradigma teórico da ecologia política e a proliferação dos movimentos ecologistas marcaram esse período. A ecologia começa a ser vista como uma ciência digna de ser ensinada juntamente com as outras ciências naturais. Nesse sentido, merece destaque a Conferência de Belgrado (1975), que estimulou um processo de reflexão sobre os problemas do Planeta, buscando traçar um marco internacional para o desenvolvimento da educação relativa ao meio ambiente e à Conferência de Tbilisi (1977), na qual se estabeleceram os critérios e diretrizes que deveriam inspirar o desenvolvimento desse movimento educativo nas décadas seguintes. Vale ressaltar, entretanto, que, embora recheados de boas intenções, os marcos internacionais não conseguiram fortalecer a EA - seja no nível regional, seja em escala planetária.

O contexto histórico-cultural no qual emerge a preocupação ecológica no Brasil foi marcado pelo contexto da ditadura militar, que consolidava um regime autoritário e desenvolvimentista, que gerava uma profunda degradação ambiental e que pretendia atrair os capitais estrangeiros para o País.

Nessa época, o Estado brasileiro cria diversas instituições para gerir o meio ambiente, porém, a lógica dessas instituições foi "determinada pela política global de atração de investimentos e não pelo valor intrínseco da questão ambiental” (GONÇALVES, 1990, p.15). O ano de 1971 marca a história do movimento ambientalista gaúcho, com a fundação, em Porto Alegre/RS, da Associação Gaúcha de Proteção à Natureza (AGAPAN), uma das primeiras associações 
ecológicas a surgir no Brasil e na América Latina, a qual inicialmente teve sua luta voltada à defesa da fauna e flora; combate à mecanização exagerada no solo; combate à poluição causada pelas indústrias e veículos; combate à poluição dos cursos de água e combate à poluição por agrotóxicos.

O início dos anos 70 é marcado pela apresentação de novas Diretrizes Curriculares para o Ensino de Primeiro Grau no RS, seguindo as orientações da mais "sofisticada" reforma educacional pensada para o País para o período (Lei 5.692/71). Essa lei, assim como as leis educacionais estabelecidas em outros países na época, estimularam a confecção de projetos curriculares que "respondiam a toda uma área ou matérias, às vezes relacionando mais de uma [no caso do currículo por atividades], com a pretensão de oferecer planos cuidadosos, sob a forma de materiais de qualidade, que difundissem novos conteúdos, elaborados com modelos de ensino-aprendizagem inovadores." (GIMENO, 2000, p. 211). As Diretrizes mantinham proposições derivadas do ideário escolanovista combinadas com concepções derivadas do tecnicismo.

O estudo do meio ambiente na escola, de responsabilidade do ensino de Ciências Naturais, deveria "evidenciar e facilitar o estudo das relações entre os seres na Natureza, esperando-se que, através do programa escolar, o aluno possa perceber o mundo como um sistema dinâmico" (RIO GRANDE DO SUL, 1972, p. 50). Também deveria estimular a observação da "beleza e da ordem da natureza, relacionando-as com a existência de um Ser Supremo" (RIO GRANDE DO SUL, 1972, p. 11).

Os programas oficiais de educação gaúcha, ainda na década de 70, buscavam objetivos de aprendizagem em termos de conduta. Foi adotada uma posição pedagógica ao invés do estímulo à inovação com base na experimentação. Desse modo, incentivaram-se doutrinamentos e a adoção, por parte dos professores, de posições que não haviam sido assimiladas com a profundidade necessária para dirigir suas práticas. Provavelmente, como apresentavam propostas teóricas muito distantes daquela que era familiar à maioria dos professores, os livros didáticos passaram a se constituir nos verdadeiros planos de ensino: 
determinavam os objetivos, os conteúdos a serem ensinados, as atividades a serem desenvolvidas em classe, além de eles próprios se tornarem a forma mais freqüente de trabalho em classe.

Nos livros didáticos, o ambiente é apresentado de forma fragmentada, o que podemos verificar na abordagem do conceito de natureza: por exemplo, o tratamento ao conteúdo relativo à água, ar e solo é absolutamente desvinculado das suas interações no ambiente. Também os seres vivos são apresentados de forma isolada, sendo o ambiente somente o local onde vivem, sem nenhum destaque para as interações entre os fatores ambientais e as características que permitem a sua sobrevivência nesse ambiente.

Os livros apresentam a natureza com uma visão mecanicista, fragmentada e mostrando relações somente do ponto de vista humano, como se o ambiente tivesse sido criado para servi-lo; ou seja, trazem explícita ou implicitamente padrões culturais que reforçam o antropocentrismo. Segundo Grün (1996), a ética antropocêntrica está ligada ao surgimento e consolidação do paradigma mecanicista.

Num estudo realizado por Sato (1992), com 400 livros didáticos do Brasil e Inglaterra, a visão utilitarista e ecológica da Educação Ambiental é evidente, negligenciando um campo social mais fecundo. Ainda que a Inglaterra não utilize os livros didáticos de forma tão sistemática como o Brasil, os conceitos, exercícios, programa curricular ou tendências políticas são fortemente enraizados na ideologia dos livros didáticos. Entretanto, a autora considera que o valor do texto está na dependência da formação crítica do professorado, que, por meio de visão de mundo, pode evidenciar as falhas dos livros didáticos e produzir bons programas educativos, ou simplesmente aceitar as ideologias hegemônicas, tornando-se mero reprodutor das culturas dominantes.

Em 1977, é proposto pela SEC/RS o Projeto Verde Rio Grande, que visava conscientizar a comunidade sobre o valor da árvore (na conservação do solo e da água, na produção de oxigênio, no embelezamento do ambiente físico, no fornecimento de alimento e matéria-prima) e integrá-la no trabalho de plantio e preservação de árvores, abrangendo as escolas de $1^{\circ}$ e $2^{\circ}$ graus das 29 DEs e 
respectivas comunidades do Estado, durante o período de maio de 1977 a janeiro de 1978. O projeto Verde Rio Grande era justificado tendo em vista o desenvolvimento acelerado da tecnologia, a crescente demanda de matéria-prima, o desenvolvimento desordenado das comunidades urbanas, a maior necessidade de consumo, o aumento considerável de água de lavoura na zona rural e a conseqüente derrubada das árvores (RIO GRANDE DO SUL, 1977, s.p.).

$\mathrm{O}$ material encaminhado às escolas continha também idéias básicas a serem trabalhadas e sugestões de atividades: é importante ressaltar que inclusive um cronograma de execução do Projeto foi proposto pela SEC/RS. Poucas tarefas eram de responsabilidade da escola: na prática, coube a ela apenas o desenvolvimento das atividades com os alunos. O planejamento, acompanhamento e avaliação do Projeto ficaram a cargo de setores da SEC/RS e das DE. No ano seguinte (1978), com o intuito de orientar as escolas estaduais a aproveitarem as áreas disponíveis nas mesmas, sensibilizando a escola e a comunidade no sentido de tornar o ambiente escolar mais belo e favorável à realização de atividades práticas de utilização e preservação da natureza, estimulando o respeito e a responsabilidade pelo meio ambiente e colaborando no melhor desenvolvimento das atividades práticas das Técnicas, foi lançado pela SEC/RS o Projeto Natureza. Novamente, no documento encaminhado às escolas, tudo estava definido: objetivos (gerais e específicos), a população-alvo, quem deveria coordenar, como deveria ser o desenvolvimento do trabalho e o processo de avaliação, inclusive como deveriam acontecer o processo de sensibilização, sugestões de atividades disciplinares e interdisciplinares e o detalhamento das tarefas.

No final dos anos 70, iniciam-se na escola as discussões sobre os riscos ambientais. São introduzidas nos livros-textos escolares noções sobre a importância da conservação dos recursos naturais e sobre os possíveis prejuízos da poluição das águas e do ar, erosão, desmatamento, queimadas... Estava implícita nessa forma de EA a premissa de que os problemas ambientais são causados pela falta de conhecimentos e que a solução, portanto, está na informação. Sabemos que esse problema é muito mais complexo, pois apenas conhecer os 
riscos não é suficiente. Uma prova disso é que os países mais poluídos, nesse período, eram os mais desenvolvidos do ponto de vista científico, tecnológico e também em seus sistemas educativos.

No Rio Grande do Sul, nessa época, as estratégias educativas que visavam a resolução de problemas raramente foram favorecidas. Ao contrário, a escola rural, especialmente através do Clube Agrícola, contribuiu, nos anos 60 e 70, para "modernizar" a agricultura, para formar um mercado consumidor para a produção de instrumentos, adubos, insumos e defensivos agrícolas. E, para ensinar esse novo modo de trabalhar na terra, as escolas rurais tinham a maior parcela dos seus gastos com despesas com produtos químicos, adubos, fertilizantes, inseticidas, sementes, mudas (especialmente de frutíferas e ornamentais), implementos e instrumentos agrícolas.

\section{A EA nos anos 80: a discussão sobre os riscos ambientais na escola e o incremento da EA no Estado}

No início dos anos 80, vivíamos um esgotamento do regime militar. É um período em que o movimento estudantil e outros setores sociais começam a se reorganizar no Brasil, reivindicando liberdade de associação, democratização do regime, eleições livres, anistia ampla, geral e irrestrita aos exilados, perseguidos e prisioneiros políticos do regime. Nasce no país a formação de uma consciência crítica, iniciando a construção de uma identidade ambientalista nacional, de educadores ambientais, fortalecida também pelo retorno de exilados políticos que vivenciaram movimentos ambientalistas europeus, contribuindo com o movimento ecológico de nosso País.

Nesse período, o movimento social gaúcho, através da AGAPAN, liderado por José Lutzemberger, aliado a outros movimentos que abraçam a causa ecológica, dá os primeiros sinais de reação mais sistematizada da sociedade civil às agressões à natureza. $\mathrm{O}$ movimento ecológico começa a ganhar maior espaço, contribuindo no processo de ecologização da mentalidade de contingentes qualitativamente importantes da população e aumentando a percepção da degradação ambiental na sociedade. 
Apesar de as lutas ecologistas não terem conseguido conter a degradação, foi no transcorrer dessas lutas que se foi constituindo a identidade coletiva do movimento ecológico (VIOLA, 1992).

$\mathrm{Na}$ década de 70, ocorrem os primeiros encontros de EA no Brasil e a EA começa a fazer parte dos debates políticos e acadêmicos e das atividades pedagógicas cotidianas. Antes de terminar a primeira metade dos anos 80, e coincidindo com o final do regime militar, começam a surgir as primeiras publicações científicas em nível nacional sobre EA.

Em 1980 e 1986, são apresentadas pela SEC/RS novas Diretrizes Curriculares para o Ensino de $1^{\circ}$ Grau, mantendo proposições semelhantes àquelas apresentadas no início da década de 70. Nas séries iniciais do Ensino Fundamental, a escola deveria colaborar para proteger os recursos do meio ambiente próximo; observar seres, fatos e fenômenos do meio ambiente próximo; e estabelecer relações entre seres, fatos e fenômenos do meio ambiente próximo, discriminando características, atributos e propriedades.

Até meados dos anos 80, os planos e documentos da Educação Pública gaúcha vinham historicamente sendo formulados em gabinetes, por equipes técnicas. O currículo, entendido como um compêndio de conteúdos ou como um conjunto de objetivos a serem alcançados junto com os alunos, era apresentado às instituições escolares para que o desenvolvessem. Os projetos curriculares eram elaborados por especialistas que também preparavam os materiais para serem experimentados, testados, reescritos, divulgados e aplicados. A eles cabiam as decisões iniciais e finais.

Durante todo esse período, em tudo o que foi pensado para a escola pública "houve um apelo pela superação de concepções de execução; a padronização do conhecimento escolar com o interesse de administrá-lo e controlá-lo; e a desvalorização do trabalho crítico e intelectual de professores e estudantes pela primazia de considerações práticas.” (GIROUX, 1997, p. 159). Sempre coube aos especialistas em currículo, avaliação, etc. a tarefa de concepção, ao passo que aos professores coube apenas a tarefa de implementação. O que está subjacente a esta forma de planejamento é o controle do comportamento dos professores, tornando-o comparável e previsível entre as diferentes 
escolas e populações de alunos. O efeito disso "não se reduz somente à incapacidade dos professores para afastá-los do processo de deliberação e reflexão, mas também para tornar rotina a natureza da pedagogia de aprendizagem e de sala de aula" (op. cit., p. 160).

A história nos mostrou que, em muitos casos, a distância das propostas das concepções dos professores e das condições das escolas levou a uma deficiente aplicação e a poucas mudanças nas atividades de ensino. Foi evidente que as potenciais idéias inovadoras sobre o conteúdo e sobre a metodologia, presentes nestes documentos, ao não contar com os professores e com as condições concretas da realidade, ficavam apenas nos documentos ou eram deformadas e empobrecidas em sua aplicação.

Essa prática reforçou entre os professores a idéia de que o plano era uma atividade profissional especializada que se realizava fora do âmbito de ação dos profissionais práticos, deixando para os docentes e alunos o papel de consumidores, não de atores, do plano curricular. Também "a noção de que os estudantes têm histórias diferentes e incorporam experiências, práticas lingüísticas, culturas e talentos diferentes, é estrategicamente ignorada dentro desta lógica" (GIROUX, 1997, p. 16).

No ano de 1988, é apresentada aos professores gaúchos uma proposta para envolvimento dos mesmos na construção do currículo da Escola Gaúcha, em um processo denominado Reconstrução Curricular. Esse trabalho começou a ser desenvolvido por professores de escolas, Delegacias de Educação, Secretarias Municipais de Educação, em parceria com universidades. A idéia inicial era de que o processo de Reconstrução Curricular deveria ser diferenciado, flexível e adaptado a cada realidade: cada região, município e escola deveria construir, com a participação de Instituições de Ensino Superior, através dos Programas Regionais de Ação Integrada (PRAI), a sua proposta pedagógica.

A ênfase, segundo a Secretaria de Educação, deveria ser o processo e não mais o produto. Ele diferiu substancialmente das anteriores, pois buscou apoiar-se numa caracterização da realidade educacional do Estado e em reflexões feitas em encontros regionais com os envolvidos. O trabalho provocou discussões e debates sobre os fundamentos das 
diferentes áreas do conhecimento. Em 1990, o Estado do Rio Grande do Sul havia construído a sua proposta pedagógica, como fruto do trabalho realizado de 1988 a 1990, não contemplando a EA na mesma.

Nos anos 80, uma grande quantidade de eventos de EA (Encontros, Seminários, Conferências, Semanas, Cursos) aconteceram na capital e nos municípios do interior do Estado, promovidos principalmente por universidades e órgãos de meio ambiente. No final dessa década (1988), é criada uma Comissão de Educação Ecológica da Secretaria de Estado de Educação e em 1989 é instaurada uma Assessoria Especial para Assuntos de EA nas DEs, integrada ao grupo pedagógico da Secretaria de Educação.

Em 1991, com a substituição do governo estadual, esse processo de reconstrução curricular foi interrompido, sendo substituído por programas de treinamento de professores, através do Projeto Melhoria da Qualidade do Ensino, que visava a atualização e o aperfeiçoamento dos professores da rede pública estadual de ensino e que tinha o ensino a distância como metodologia desencadeadora do trabalho.

Os materiais utilizados durante o período foram planejados, organizados, elaborados e avaliados por equipes de Instituições de Ensino Superior do Rio Grande do Sul, pensando na formação de um professor único, novamente sendo esquecido o ensino rural. Também no período, foi distribuída uma grande quantidade de livros sobre temáticas específicas das áreas. Durante as férias letivas, os professores estudavam, individualmente e em grupos, os materiais encaminhados às escolas e em seguida eram elaboradas propostas de ensino que eram encaminhadas à DE da região, e esta as enviava à Secretaria Estadual de Educação. A questão ambiental foi pensada apenas para o ensino de Biologia, no $2^{\circ}$ grau.

\section{A EA nos anos 90 e 2000: a "explosão" da EA nas agendas políticas e nas preocupações sociais}

É no início dos anos 90 que ocorre uma grande expansão da EA no Brasil, especialmente em função da realização da Conferência das Nações Unidas para o Meio Ambiente e Desenvolvimento (Eco 
92). Houve um aumento considerável na produção científica: inúmeros livros e artigos são publicados por editoras de renome nacional e por revistas de divulgação científica. Também começa nesse período uma grande procura por cursos de EA, que são oferecidos por universidades, Secretarias de Educação e de Meio Ambiente dos Estados e por organizações não governamentais.

Nessa década, ocorrem não só inúmeros encontros nacionais de EA como também vários encontros estaduais, regionais e municipais no RS. A temática que antes era específica dos movimentos ecológicos foi internalizada de diferentes maneiras por diferentes atores da sociedade civil.

Em 1994, a Política Educacional Brasileira, seguindo o modelo vindo da Espanha, incluiu o tema meio ambiente como transversal, ou seja, como uma temática a ser estudada em todas as áreas do conhecimento presentes no cotidiano escolar, na proposta dos Parâmetros Curriculares Nacionais (PCN). Em 1996, ano em que os PCN foram encaminhados às escolas gaúchas, é iniciado no Estado um processo de construção coletiva do Padrão Referencial de Currículo (PRC), seguindo os mesmos moldes dos PCN. Em 1996, foi apresentado aos professores do Rio Grande do Sul o documento básico do Padrão Referencial de Currículo, que, segundo a Secretaria Estadual de Educação, foi o resultado do estudo de inúmeras equipes de professores de todo o Estado, envolvendo Escolas, Delegacias de Educação e Instituições de Ensino Superior (RIO GRANDE DO SUL, 1998).

Os PCN procuram dar resposta às contradições entre a necessidade de dar um espaço próprio ao estudo do meio ambiente e a natureza intrinsecamente interdisciplinar e transversal dos conhecimentos que esta propõe. A proposta de temas transversais, além de modificar a organização tradicional do conhecimento e o funcionamento das instituições escolares, deposita no professor a iniciativa de incorporar temas e desenvolver atividades de natureza local, assim como de proporcionar articulações com outras áreas do conhecimento e com a realidade onde vivem os estudantes.

O meio ambiente é um tema transversal, pois não aparece associado a alguma área específica do conhecimento, mas a todas elas em 
geral; é um movimento inovador, cujos princípios afetam o sistema educativo; gira em torno de problemas que afetam o sistema educativo e o sistema social em seu conjunto, na medida em que estes se relacionam com outros sistemas (ecológicos, econômicos, etc.). Por ser transversal, a EA apresenta a necessidade de que a comunidade educativa incorpore seus princípios em todas e em cada uma das fases do desenvolvimento curricular, tanto em nível de objetivos como de conteúdos ou de metodologia. Por essa razão, é fundamental a formação de professores para trabalhar a partir dessa ótica educativa, que supõe um forte replanejamento de muitos modos de fazer tradicional.

Defendemos a idéia de que o meio ambiente é efetivamente um tema transversal, não apenas porque pode ser abordado por todas as disciplinas escolares, mas porque procura relacionar diversos tipos de reflexões: a ecológica, a metodológica e a pedagógica. É também um tema transversal porque coloca sobre uma única mesa pontos de vista e interesses diferentes: desde associações ecologistas a professores que querem inovar, desde entidades locais que buscam responder às exigências e às emergências ambientais a cidadãos comuns que se preocupam com essas mudanças globais.

Em 1996, ano em que os PCN começam a ser encaminhados às escolas gaúchas, é iniciado no Estado um processo de "construção coletiva" do Padrão Referencial de Currículo (PRC), seguindo os mesmos moldes dos PCN. Em 1998, a $1^{\text {a }}$ Versão do PRC foi apresentada à comunidade educacional gaúcha, com a EA fazendo parte dos temas apresentados como Temas de Relevância Social. A proposta de EA, apresentada em 4 páginas, contém uma breve fundamentação e caracterização da mesma, dando ênfase ao processo de aquisição de "saberes" (conhecimentos), do "saber fazer", incentivando a elaboração do "ser" através do "conviver" com os outros. Também apresenta os Marcos de Aprendizagem em EA: fatos, conceitos e princípios (saber); procedimentos (saber fazer) e valores (ser/conviver) que a EA escolar gaúcha precisa desenvolver. Apenas esse material sobre EA chegou até as escolas estaduais para subsidiar o processo de elaboração dos Projetos Políticos Pedagógicos (PPP) e 
Planos de Estudo (PE), porém, a questão ambiental foi incorporada apenas nos PE das disciplinas da área de Ciências Naturais.

No período de 1999-2002, por meio da Constituinte Escolar (movimento de construção da escola democrática e popular, que teve a participação das comunidades escolares gaúchas, dotando as escolas de autonomia no desenvolvimento do currículo), as comunidades escolares fizeram a opção pela inserção da EA nos currículos escolares gaúchos. Propõe-se que a EA deva deixar de ser um assunto marginalizado e isolado no interior dos sistemas educativos e comece a encontrar um lugar apropriado dentro do projeto educativo das escolas, bem como a fortalecer os seus laços com outros aspectos da educação. Nesse sentido, foram propostos pelas Coordenadorias Regionais de Educação (CRÊE) cursos de curta duração voltados à formação continuada de professores e inúmeros projetos de $\mathrm{EA}$ foram desencadeados pelas escolas.

Atualmente, a SE/RS, em parceria com a Coordenação Geral de EA do MEC, por meio do Programa Vamos Cuidar do Brasil com as Escolas, vem desenvolvendo um processo de formação de formadores em EA. Esse programa busca implantar na educação formal a dimensão ética, política, científica, pedagógica e estética da EA e incentivar a formação continuada de novas lideranças.

Convém ressaltar que neste início de milênio inúmeras universidades gaúchas vêm desenvolvendo programas de formação de professores em EA, bem como têm inserido a dimensão ambiental nos cursos de formação de professores em nível superior.

\section{Considerações finais}

Defendemos que o desenvolvimento do currículo de EA deve ser baseado na realidade de cada escola. Precisamos deixar de lado grandes projetos cuidadosamente planejados por técnicos e agentes especializados e valorizar tentativas mais modestas, mais próximas das escolas, desenvolvidas pela comunidade escolar. Com isto, não queremos desobrigar o Estado das políticas educacionais e da formação docente em EA. Apenas acreditamos que o envolvimento ativo dos 
professores no desenvolvimento do currículo de EA faz das escolas um local de desenvolvimento profissional.

O currículo não muda por um ato administrativo ou pela mera apresentação formal de uma nova teoria curricular. Mudar o currículo implica que os professores mudem seus pontos de vista sobre os processos de ensino-aprendizagem e, conseqüentemente, suas formas de intervir, ou seja, o seu "saber fazer profissional".

Pesquisas para a avaliação da EA no RS na última década precisam ser desenvolvidas a fim de nos ajudarem a entender um pouco mais os sucessos e os fracassos dos processos implementados, bem como para ampliar nossas alternativas de intervenção nas questões ambientais contemporâneas a partir da atividade dos profissionais da educação.

Uma boa alternativa parece estar na orientação de que a escola jamais pode ser considerada como ilha isolada do continente em crise, buscando a parceria com a comunidade de seu entorno. Para além de um saber sistematizado nos muros da escola, o currículo deve ser compreendido como além do conteúdo programático, inscrevendo numa espiral de possibilidades culturais. E a educação, por sua vez, não deve ser vista como solucionadora de problemas, pois a visão utilitarista pode atribuir responsabilidades que não pertence somente a ela, senão a um vasto campo político, científico, artístico ou espiritual que circula na sociedade global. O papel da Educação Ambiental não se limita ao alicerce técnico-científico, mas, sobremaneira, na ressignificação do existir. E, sobremaneira, para além do ser, o que podemos vir a ser.

\section{Referências bibliográficas}

ABRANTES, P. Imagens de Natureza, imagens de Ciência. Campinas: Papirus, 1998.

CARVALHO, I.C. As transformações na cultura e o debate ecológico: desafios políticos para a educação ambiental. In: NOAL, Fernando Oliveira; REIGOTA, Marcos; BARCELOS, Valdo Hermes de Lima (org.). Tendências da Educação Ambiental Brasileira. Santa Cruz do Sul: EDUNISC, 1998, p. 113-126. 
GONÇALVES, C.W.P. Os (des) caminhos do meio ambiente. 2. ed. São Paulo: Contexto, 1990.

GIMENO, J. O currículo: uma reflexão sobre a prática. 3. ed. Porto Alegre: Artes Médicas, 2000 .

GIROUX, H.A. Os professores como intelectuais - rumo a uma pedagogia crítica da aprendizagem. Porto Alegre: Artes Médicas, 1997.

GRITTI, S. O Papel da Escola Primária rural na penetração do Capitalismo no campo. 1999. Dissertação de Mestrado. (Mestrado em Desenvolvimento Social) Universidade Católica de Pelotas, Pelotas.

GRÜN, M. Ética e Educação Ambiental: a conexão necessária. Campinas: Papirus, 1996.

GUATTARI, F. As três ecologias. Campinas: Papirus, 1991.

ORELLANA, I. La comunidad de aprendizaje en educación ambiental. Una estrategia pedagógica que are nuevas perspectivas en el marco de los cambios educacionales atuales. Tópicos en Educación Ambiental, México, v. 3, n.7, p.43-51, ago. 2001.

RIO GRANDE DO SUL. Secretaria da Educação e Saúde Pública. Programa de Estudos Naturais. Revista do Ensino, Porto Alegre, v.2, n.5, jan.1940, p.71-80.

RIO GRANDE DO SUL. Secretaria da Educação e Cultura. Os Estudos Naturais na Escola Primária - Comunicado expedido pelo CPOE do R.G.S. Revista do Ensino, Porto Alegre, p. 26-30, março 1956.

. Diretrizes Curriculares para o Ensino de $1^{\circ}$ Grau no Rio Grande do Sul- Currículo por Atividades. Porto Alegre, 1972. . Diretrizes Curriculares para o Ensino de $1^{\circ}$ Grau no Meio Rural. Porto Alegre, 1974. 
- Projeto Verde Rio Grande. Porto Alegre, 1977.

. Projeto Natureza. Porto Alegre, 1978.

- Ensino de $1^{\circ}$ Grau no Rio Grande do Sul: Diretrizes Curriculares da Área de Ciências. Porto Alegre, 1980.

- Uma Proposta de Currículo para o Ensino de $1^{\circ}$ Grau: Currículo por Atividades. Porto Alegre, 1986.

RIO GRANDE DO SUL. SECRETARIA DA EDUCAÇÃO. Padrão Referencial de Currículo. Temas de Relevância Social - Ensino Fundamental. Porto Alegre, 1998.

Constituinte Escolar - construção da Escola Democrática e Popular. Fundamentação, objetivos e momentos da Constituinte Escolar. Porto Alegre, ago. 1999.

- Constituinte Escolar - Princípios e Diretrizes para a Educação na Escola Pública Estadual. Porto Alegre, 2000. (mimeo.)

. Constituinte Escolar - construção da Escola Democrática e Popular - Sistematização do $2^{\circ}$ Momento - caderno 4. Porto Alegre, abr. 2000.

SATO, M. How the environment is written. A study of the utilization of textbooks in Brazil and England. 2002, 145p. M. Phil. Thesis. University of East Anglia, Norwich.

SAUVÉ, L.; ORELLANA, I. A Formação Continuada de Professores em Educação Ambiental: a proposta EDAMAZ. In: SANTOS, J.E.; SATO, M. A Contribuição da Educação Ambiental à Esperança de Pandora. São Carlos, RIMA, 2001, p. 273-288.

SILVA, R.I.T. da. Clubes agrícolas escolares: educação rural. Revista do Ensino. Porto Alegre: SEC, n.13. p. 48-53, jun. 1940.

. Escola Primária Rural. 3. ed. Porto Alegre: Globo, 1970. 
VIOLA, E. O movimento ecológico no Brasil (1974-1986): do ambientalismo à ecopolítica. In: PÁDUA, José Augusto (org.) Ecologia e Política no Brasil. 2.ed. Rio de Janeiro: Espaço e Tempo: IUPERJ, 1992, p. 63-109.

VIOLA, E.; LEIS, H.R. Desordem global da biosfera e a nova ordem internacional: o papel organizador do ecologismo. In: LEIS, Héctor R. (org.) Ecologia e Política Mundial. Rio de Janeiro: FASE: AIRI/PUC-Rio; Petrópolis: Vozes, 1991, p. 23-50. 